\title{
De bijzondere strafrechtelijke positie van culpose misdrijven
}

Prof.mr D.H. de Jong*

\section{Inleiding}

In deze bijdrage wordt ingegaan op de positie die de zogenoemde culpose misdrijven of schuldmisdrijven innemen in het strafrecht, een positie tussen de opzetmisdrijven en de overtredingen in. Aan de orde komen de aard van de culpose misdrijven, de verhouding van deze misdrijven met de opzetmisdrijven enerzijds en met de overtredingen anderzijds, de ontwikkeling van het bij deze misdrijven centraal staande schuldbegrip en de hoogte van de wettelijke strafbedreigingen.

'Schuld' als bestanddeel van de culpose misdrijven is globaal te omschrijven als: aan onachtzaamheid, onvoorzichtigheid, nalatigheid van een zekere graad (ernst) te wijten gevolgen. Deze schuld duiden we aan met de Latijnse term culpa. Kort gezegd: culpa is aanmerkelijke onvoorzichtigheid.

Ter oriëntatie noem ik enkele culpose misdrijven. Dood door schuld en zwaar lichamelijk letsel door schuld zijn strafbaar gesteld in de artt. 307 en 308 Wetboek van Strafrecht (Sr); voorzover het hierbij gaat om verkeersongevallen voorziet art. 6 Wegenverkeerswet (WVW) meer specifiek in strafbaarheid. Culpose radioactieve besmetting en culpose milieuverontreiniging worden straf-baar gsteld in art. 161 quinquies Sr, respectievelijk art. 173b Sr. Brand, explosie en overstroming door schuld worden strafbaar gesteld in art. $157 \mathrm{Sr}$.

Het is interessant om de aan culpose misdrijven verbonden wettelijke strafbe-dreigingen te vergelijken met de op opzetmisdrijven gestelde straffen enerzijds en met de op overtredingen gestelde straffen anderzijds. Vergelijken wij op het punt van bedreigde vrijheidsstraffen eerst culpose misdrijven met verwante opzetmisdrijven, dan valt een zeer groot verschil op. Dood door schuld kent in art. $307 \mathrm{Sr}$ een strafmaximum van 9 maand, terwijl op doodslag (opzettelijke levensberoving) maximaal 15 jaar staat. Is opzettelijk en met

* Hoogleraar Straf(proces)recht aan de Faculteit der Rechtsgeleerdheid van de Rijksuniversiteit Groningen. 
voorbedachte raad gehandeld, dan gaat het om moord en is het strafmaximum levenslange gevange-nisstraf. Culpose radioactieve besmetting wordt met maximaal twee jaar be-straft, terwijl op opzettelijke radioactieve besmetting maximaal levenslang staat. Dergelijke zeer grote verschillen in strafbedreiging zien wij heel vaak tussen culpose misdrijven en hun opzetvarianten. Dit roept sterk de vraag op, waar de grens ligt tussen de bovenkant van culpa (hoogst roekeloos handelen) en opzet (doelbewust handelen). Interessant is hier de vergelijking met het Duitse straf-recht. Dit vertoont sterke verwantschappen met ons strafrecht, maar kent duide-lijk hogere strafmaxima bij culpose misdrijven. Dientengevolge ligt daar de vraag: 'was het opzet of slechts schuld?' wat minder scherp dan bij ons.

Vergelijken wij op het punt van bedreigde vrijheidsstraffen de culpose misdrijven vervolgens met de overtredingen, dan zien wij ook daar een belangrijk verschil in hoogte. Op verkeersovertredingen bijvoorbeeld staat maximaal 2 maand hechtenis. Dit is aanzienlijk lager dan de op dood door schuld en zwaar lichamelijk letsel door schuld bij gelegenheid van een verkeersongeval gestelde maximumstraffen, zéker na de boven reeds even aangestipte recente forse ver-hoging van de op deze misdrijven van art. 6 WVW gestelde maximumstraffen. Ook dit roept de vraag op naar de grens van het culpabegrip, ditmaal de ondergrens. Het ligt voor de hand om te veronderstellen dat die duidelijk hogere strafbedreiging voor culpose misdrijven in vergelijking met overtredingen zal zitten in de ernst van het ingetreden gevolg én in de culpa (onachtzaamheid, onvoorzichtigheid, nalatigheid van een zekere graad/ernst). Waar ligt nu de grens tussen de onderkant van culpa en het geval dat er slechts sprake is van een overtreding? Of is er misschien steeds als de overtreding tot een fataal gevolg leidt (dood of zwaar lichamelijk letsel) sprake van een culpoos misdrijf?

De bovengrens en de ondergrens van het culpabegrip zullen hieronder nader worden belicht, evenals de aan culpose misdrijven verbonden strafbedreigingen.

\section{Karakterisering van culpa}

Wat moeten we precies onder culpa verstaan en hoe heeft het culpabegrip zich ontwikkeld sinds de invoering van ons Wetboek van Strafrecht in 1886 ?

Psychologiserende aanpak Aanvankelijk werd culpa overwegend als een psychische toestand, een negatief gewaardeerde psychische toestand van de dader benaderd. De geestestoestand van de dader schiet op het moment van handelen 
tekort. Er was dus sprake van een psychologiserende aanpak. Het psychische aspect werd verder uitgewerkt in het onderscheid tussen onbewuste en bewuste schuld. Van onbewuste schuld was sprake als de dader geen gevaar had gezien of beseft. Een voorbeeld is de automobilist die in zijn hoofd zo met andere zaken bezig is dat hij daardoor een op rood staand verkeerslicht in het geheel niet opmerkt, met fatale gevolgen. Men spreekt van bewuste schuld als de veroorzaker van het fatale gevolg wel gevaar zag, maar dit gevaar onderschatte. Een voorbeeld is de automobilist die ziet dat het verkeerslicht op rood is gesprongen, maar toch doorrijdt omdat hij haast heeft en denkt dat hij de situatie onder controle heeft, waarna een botsing met fatale gevolgen ontstaat.

Verder wordt voor culpa aanmerkelijke onachtzaamheid/onoplettendheid/ onvoorzichtigheid geëist. Niet de allerlichtste mate van tekortschieten levert reeds culpa op, maar een aanmerkelijke mate is nodig. Men spreekt in dit verband wel van culpa levis (lichte schuld) en culpa lata (beduidende schuld). Culpa levis is de lichtste mate van schuld. Deze lichtste mate is volgens de gangbare dogmatiek al voldoende om de steeds voor strafbaarheid vereiste verwijtbaarheid op te leveren. Als iemand bijvoorbeeld een verkeersovertreding begaat, gaat hij/zij alleen vrijuit als bij hem/haar álle schuld ontbreekt. Voor culpa als bestanddeel van de culpose misdrijven is daarentegen culpa lata (aanmerkelijke schuld) vereist. Het is overigens de vraag of deze extra eis van aanmerkelijke schuld in de rechtspraktijk veel inhoudt. Hierop kom ik nog terug.

De onderscheiding tussen onbewuste en bewuste schuld is niet een onderscheiding tussen lichtere en zwaardere vormen van culpa. Zo kan onbewuste schuld onder omstandigheden wijzen op een dermate grote onverschilligheid jegens de medemens dat zij als ernstiger is aan te merken dan bepaalde vormen van bewuste schuld. Het onderscheid tussen onbewuste en bewuste schuld was meer een hulpmiddel om de psychische component van de culpa te construeren. Ver-der werd in de zestiger/zeventiger jaren vooral de rechtvaardiging van het bestraffen van bepaalde vormen van onbewuste schuld als problematisch gevoeld. Instructief in dit verband is bijvoorbeeld de strafmotivering van de arrondissementsrechtbank te Rotterdam ${ }^{2}$ in een strafzaak die in de vijftiger jaren werd gevoerd tegen een verpleegster door wier fatale fout (het verkeerde flesje uit de medicijnkast pakken) een te opereren patiënt was overleden. De rechtbank achtte de verpleegster schuldig aan het misdrijf dood door schuld (art. $307 \mathrm{Sr}$ ). Bij het bepalen van de op te leggen straf overwoog de rechtbank vervolgens:

1 Rb. Rotterdam 16 mei 1950, NJ 1950, 845. 
'De Rechtbank neemt hierbij in het bijzonder in aanmerking dat verdachte ter terechtzitting heeft getoond diep onder de indruk te zijn van de gevolgen van het gepleegde feit, en haar besef dat door haar toedoen een mens het leven heeft verloren, welk besef voor een persoon als verdachte, die zich als verpleegster ten doel heeft gesteld anderer lijden te verzachten, en zo mogelijk anderer leven te redden, bijzonder pijnlijk is en voor haar reeds een ernstige morele straf betekent. Bovendien neemt de rechtbank in aanmerking de bijzonder gunstige inlichtingen welke omtrent haar persoon en werk zijn verkregen.'

De rechtbank legde de verpleegster vervolgens 1 dag hechtenis voorwaardelijk op. Hieruit komt in alle scherpte het problematische van strafoplegging in dit ge-val van onbewuste schuld naar voren.

Uiterlijke maatstaven ter vaststelling van culpa

De discussie onder strafrechtjuristen over de rechtvaardiging van het bestraffen van bepaalde vormen van onbewuste schuld is inmiddels verflauwd. Enerzijds lijkt men erin te berusten dat de strafbaarstelling van onbewuste schuld aan een noodlottige afloop niet op erg bevredigende wijze theoretisch kan worden onder-bouwd. Anderzijds heeft de aandacht zich verplaatst van de psychische component van de culpa naar de vraag, aan de hand van welke uiterlijke maatstaven men de schuld, de culpa kan vaststellen. Inderdaad kan de culpa (doorgaans) aan het gedrag worden afgelezen. En dat is nog sterker geworden doordat de over-heid voor steeds meer sectoren van het maatschappelijk leven gedragsvoor-schriften in het belang van de veiligheid heeft uitgevaardigd: verkeersvoorschriften, veiligheidsvoorschriften voor bedrijven, ziekenhuizen e.d., milieuvoorschriften, voorschriften voor de bouw, voorschriften voor het installeren van, en werken met elektrische apparatuur, enz.

\section{Ontmanteling van de culpa}

Aldus is culpa ongeveer geworden tot, vrijwel versmald tot: overtreding van door wet- of regelgever uitgevaardigde voorschriften. Het gaat hier bepaald niet om een recente ontwikkeling. In deze geldende benadering heeft het vereiste van aanmerkelijke schuld zijn betekenis eigenlijk helemaal verloren. Want in al die door mij bedoelde sectoren van het maatschappelijk leven is de mens als functio-naris gaan gelden. Zo bekleden wij allen iedere dag de functie van verkeersdeelnemer. Als er in één van die functies iets mis gaat, blijken aan de functio-naris hoge eisen te worden gesteld. Elk handelen in strijd met gedragsvoor-schriften levert dan een aanmerkelijke fout op.

Zo kunnen we wat het wegverkeer betreft uit de rechtspraak van de Hoge Raad concluderen dat het misdrijf dood of zwaar lichamelijk letsel door schuld gecon-strueerd kan worden zodra een verkeersovertreding tot een fatale afloop leidt. Het misdrijf is dus in feite gereduceerd tot een door het gevolg tot misdrijf gekwalificeerde verkeersovertreding, en de 
eis dat er sprake moet zijn van culpa, heeft geen zelfstandige betekenis op misdrijfniveau meer. Ook de automobilist die zijn best heeft gedaan hij stopte bijvoorbeeld voor de voorrangskruising, keek twee maal naar links en twee maal naar rechts, zag geen verkeer op de voorrangsweg en trok toen op, waarbij hij een door hem toch over het hoofd geziene fietser aanreed met fatale afloop - kan met succes worden vervolgd voor het culpose misdrijf van art. 6 WVW. Hij verleende immers geen voorrang en handelde dus in strijd met het Reglement Verkeersregels en Verkeerstekens (RVV).

Deze ontmanteling van de culpa-eis op misdrijfniveau is, het zij herhaald, be-paald niet van recente datum. Buiten het wegverkeer valt het bekende, uit de zestiger jaren stammende Verpleegsterarrest van de Hoge Raad $^{2}$ te noemen. De casus (die veel lijkt op de hierboven besproken Rotterdamse strafzaak) en de strafrechtelijke uitkomst zijn illustratief voor mijn betoog. Een overwerkte, maar toch dienstdoende verpleegster werd aan het einde van haar werkdag, juist toen ze het ziekenhuis verliet, van de stoep geplukt om nog te assisteren bij een spoedoperatie. In de operatiekamer heerste wanorde. Die wanorde strekte zich uit tot de kast waarin het flesje stond waaruit de te opereren patiënt een injectie moest worden toegediend. De verpleegster moest het flesje pakken en aanreiken aan de hoofdzuster. Op de plaats waar dit flesje moest staan stond een ander flesje, met een vloeistof waarvan de op het etiket vermelde naam verwarrend veel leek op de naam van de juiste vloeistof. De verpleegster keek, zoals haar geleerd was, op het etiket, maar het drong in deze situatie niet tot haar bewust-zijn door dat het niet het goede flesje was, dat ze had gepakt. Mede omdat vervolgens in strijd met de in het ziekenhuis geldende regels niet door andere, boven haar staande functionarissen gecontroleerd werd of ze het goede flesje aanreikte, kon het gebeuren dat de patiënt geïnjecteerd werd met de verkeerde vloeistof; dit had een dodelijke afloop.

De verpleegster werd vervolgd terzake van het misdrijf dood door schuld. Door haar advocaat werd het door een deskundigenverklaring ondersteunde verweer gevoerd dat bij haar geen sprake was van onoplettendheid, gehaastheid of een soortgelijk tekort aan zorgvuldigheid - zij had immers volgens de voorschriften op het etiket gekeken maar van een incidentele psychische kortsluiting (een zo-genoemde Fehlleistung), waardoor het door haar op het etiket gelezene verkeerd in haar bewustzijn was geregistreerd; dit was in de hand gewerkt door allerlei door mij zojuist aangeduide, niet aan de verdachte te wijten omstandigheden. Ook werd aangevoerd dat verschillende andere, hogere functionarissen onzorg-vuldig waren geweest. De verpleegster werd echter wegens het misdrijf dood door schuld veroordeeld (tot $f$

2 HR 19 februari 1963, NJ 1963, 512. 
100,- boete ...). De Hoge Raad achtte het cassatieberoep van de verpleegster ongegrond, omdat de feitenrechter in zijn vonnis niet hoefde in te gaan op het eerste verweer (het beroep op de Fehlleistung) en omdat medeschuld van anderen niet van invloed was op haar schuld.

Als men daarentegen serieuze, zelfstandige eisen zou stellen aan het vereiste van aanmerkelijke schuld, en dat zou ik persoonlijk willen voorstaan, dan zou een andere uitkomst dan veroordeling wegens dood door schuld denkbaar zijn geweest; dan zou wellicht een vrijspraak uit de bus zijn gekomen omdat onder het gegeven samenstel van omstandigheden niet van aanmerkelijke schuld kon worden gesproken. In zo'n benadering zou, bijvoorbeeld in het verkeersstrafrecht, het culpose misdrijf wat duidelijker kunnen worden afgezet tegenover de sfeer van de overtredingen.

Culpa of opzet?

In het bovenstaande heb ik de culpose misdrijven afgezet tegenover de over-tredingen. Voor de karakterisering van de culpa is het evenzeer nuttig om dit begrip anderzijds af te zetten tegenover opzet. Waar ligt de grens tussen opzet en culpa? De grens tussen dood, resp. zwaar lichamelijk letsel door schuld enerzijds en doodslag, resp. zware mishandeling anderzijds speelt het duide-lijkst, in elk geval het meest herkenbaar in het verkeer. Opzettelijk handelen is willens en wetens handelen; culpoos handelen is onvoorzichtig handelen. Om vat te krijgen op de grens tussen opzet en culpa te moet eerst iets over het juridische leerstuk opzet worden gezegd. Ook bij de ontwikkeling van het leerstuk van het opzet gold aanvankelijk een overwegend psychologiserende benadering van opzet: opzettelijk handelen werd gezien als handelen in een bepaalde psychische toestand. De dader wist en wilde. En ook hier werd het psychische aspect weer verder uitgewerkt, in de onderscheiding van een aantal schakeringen van opzet: oogmerk, zekerheidsbewustzijn, waarschijnlijkheidsbewustzijn, voorwaardelijk opzet. Oogmerk is het naaste doel van de handelende dader. Zekerheidsbe-wustzijn, respectievelijk waarschijnlijkheidsbewustzijn is het besef bij de dader dat zijn op een bepaald doel gerichte handelen tevens noodzakelijkerwijs, respectievelijk naar alle waarschijnlijkheid een bepaald neveneffect zal hebben; daarmee is zijn opzet niet alleen op het naaste doel, maar ook op dat neveneffect gericht. Een klassiek, uit het begin van deze eeuw stammend voorbeeld uit de jurisprudentie biedt het Hoornse taart-arrest van de Hoge $\mathrm{Raad}^{3}$. Bewezen-verklaard was dat de verdachte te Amsterdam een vrouw M.M. (de vrouw van marktmeester M. te Hoorn) opzettelijk en met voorbedachte raad van het leven had beroofd. De feiten waren aldus, dat verdachte vanuit Amsterdam aan die marktmeester een taart, waarin een letale hoeveelheid rattenkruid, had verzon-den. Na die verzending, toen hij in de trein naar Hoorn zat, was

3 HR 19 juni 1911, W 2903. 
het tot hem doorgedrongen en was hij tot 'de stellige verwachting' gekomen, dat niet alleen de marktmeester die hij wilde vermoorden, maar ook diens vrouw van de taart zou kunnen eten. Hij had toen niets gedaan om dit te voorkomen, de vrouw at inderdaad van de taart en was daaraan gestorven. De Hoge Raad overwoog dat het Hof uit een en ander had mogen afleiden:

'dat - al was des requirants beweegreden tot zijne daad alleen zijne begeerte om M. uit den weg te ruimen - toch zijn vooromschreven plan mede omvatte het dooden van die personen, die van de eenmaal bij M. bezorgde taart mochten eten en wel in het bijzonder van de verslagene M.M.'

Voorwaardelijk opzet tenslotte, de onderste laag van strafrechtelijk opzet, is het besef bij de dader dat zijn op een bepaald doel gerichte handelen tevens moge-lijkerwijs een bepaald neveneffect zal hebben, waarbij de dader het eventueel intreden van dit gevolg op de koop toeneemt; daarmee is zijn opzet niet alleen op het naaste doel, maar ook op dat neveneffect gericht. Bij de constructie van het voorwaardelijk opzet is het weten in sterk afgezwakte vorm aanwezig en is het willen cruciaal; het willen kan ook zorgen voor een verantwoorde afgrenzing hoe moeilijk ook - met zeer grove schuld, hoogst roekeloos gedrag, dus de bovenkant van culpa. Dat laat zich met name in het verkeer illustreren. Denk aan door rood licht rijden met een auto, waarbij een dodelijk ongeval (of een ongeval met zwaar lichamelijk letsel) wordt veroorzaakt. We weten allemaal dat door rood rijden niet zonder gevaar is. Maar we willen niet een dodelijk of anderszins ernstig ongeluk veroorzaken. Hier is derhalve (doorgaans) geen opzet in het spel, maar culpa. Echter kan onder bepaalde omstandigheden van voor-waardelijk opzet op dodelijke afloop worden sprake zijn. Denk aan de bankovervaller die in het bankgebouw reeds twee personen heeft doodgeschoten en vervolgens met de vluchtauto alle verkeersregels negeert en door alle rode lichten rijdt die hij tegenkomt. Als hier op een bepaald moment nog meer doden vallen, kan heel goed geredeneerd worden dat de bankovervaller zich niet alleen de mogelijkheid van zo'n afloop bewust was, maar deze mogelijke afloop ook heeft ingecalculeerd. Daarmee is het voorwaardelijk opzet op deze afloop geconstrueerd en is er dus ook voor wat betreft de verkeersdode(n) sprake van doodslag of moord. Meer algemeen kan de vraag: 'culpa of opzet'? gesteld worden bij gevallen van wegpiraterij die fataal aflopen. Doorgaans zal de dader deze afloop niet hebben gewild. Maar bij sommige ernstige vormen van wegpiraterij zal voorwaardelijk opzet op de gevolgen kunnen worden aangenomen: de dader heeft de risico's onderkend en een mogelijk fatale afloop op de koop toege-nomen.

Ook bij de strafrechtelijke benadering van het opzet zien wij een ontwikkeling waarbij de aandacht zich verplaatst van de psychische 
component van het opzet naar de vraag, aan de hand van welke uiterlijke maatstaven men het opzet kan vaststellen. Gedrag krijgt hier een normatieve betekenis: bepaald wordt of het gebeuren op grond van het gedrag van de verdachte aan hem dient te worden toegerekend als doodslag (of een ander opzetdelict). In deze benadering is het vaststellen van opzet een vorm van toerekenen van het gebeuren aan de verdachte. Dat heeft de zo sterk psychisch ingekleurde component van het willen verzwakt en daarmee het bereik van het opzet verruimd. In de toepassing door de rechter van de Opiumwet zien we een haast extreme mate van dergelijk toerekenen van opzet op grond van het gedrag van de dader, en daar is de verruiming van het opzet dan ook zeer ver voortgeschreden. Een voorbeeld biedt HR 25 november 1986, NJ 1987, 493, waarin de Hoge Raad overwoog:

'Uitgaande van de algemene ervaringsregel dat de bestuurder, tevens enige inzittende, van een hem toebehorende personenauto, waarin zich een niet onaanzienlijke hoeveelheid heroïne bevindt, met de aanwezigheid van die heroïne bekend pleegt te zijn, heeft het hof het bewezenverklaarde uit de gebezigde bewijsmiddelen kunnen afleiden, met name ook dat de verdachte opzettelijk heeft gehandeld.'

Dit komt er ongeveer op neer dat van iedereen die onder de genoemde omstan-digheden een auto bestuurt, aangenomen kan worden dat hij opzettelijk in strijd met de Opiumwet handelt. Het algemeen bekend zijn van bepaalde risico's is hier doorslaggevend en voldoende om opzet aan de dader toe te rekenen. In het verkeersstrafrecht zien we dat, zij het minder pregnant, ook wel, en dan met betrekking tot een 'commuun' delict: doodslag. Met onverminderde snelheid doorrijden bij een verkeerscontrole en daarbij inrijden op de een stopteken gevende agent, waarbij de agent opzij moet springen om het vege lijf te redden, wordt bij mijn weten door politie, officier van justitie en strafrechter vrij stan-daard aangemerkt als poging tot doodslag, zonder dat meer precies naar de individuele omstandigheden van de zich voordoende casus wordt gekeken. Dit laatste hoeft ook niet als men de component van het weten centraal stelt, wat dus kennelijk het geval is naar geldend recht. Uiteraard weet iedere automobilist dat dit echt gevaarlijk is, dat dit fout kán lopen. Zou men echter ook evenveel waarde hechten aan de andere component, het willen, dan zou men van geval tot geval nader moeten gaan kijken naar de individuele toedracht.

\section{Wegpiraterij}

Laten we in de jurisprudentie van de afgelopen 10 jaar wat nader kijken: wanneer werd grove wegpiraterij die leidde tot een ernstig ongeval met dood of zwaar lichamelijk letsel tot gevolg, met succes vervolgd als doodslag, respectie-velijk zware mishandeling (waarbij dus voorwaardelijk opzet werd aangeno-men)? 
- Allereerst zijn er de duidelijke gevallen van het gebruiken van de auto als instrument. Ik noem twee voorbeelden. Een automobilist achtervolgde een motorrijder, als agressieve reactie op diens wijze van rijden; hij haalde hem in en sneed hem zodanig dat deze tegen de vangrail reed en zwaar gewond raakte. Deze automobilist werd vervolgd en veroordeeld terzake van zware mishandeling. ${ }^{4}$ Een spookrijder reed welbewust op de autosnelweg tegen de stroom in om mensen schrik aan te jagen; wegens het daarop volgende verkeersongeval met ernstige afloop werd hij voor een opzetmisdrijf veroor-deeld.

4 HR 10 maart 1992, DD 92.266. 
- Daarnaast zijn er andere gevallen waarin voor een opzetmisdrijf is vervolgd en veroordeeld. Een treffend voorbeeld biedt HR 17 december 1996, NJ 1997, 245. lemand reed in een gestolen auto een politieauto aan en probeerde vervolgens aan de politie te ontkomen. Hij reed met zeer hoge snelheid, tot ongeveer $120 \mathrm{~km} / \mathrm{u}$, door Amsterdam en negeerde verkeerstekens. Nadat hij al een andere auto had geraakt, reed hij met een snelheid van ongeveer $100 \mathrm{~km} / \mathrm{u}$ langs een rij voor een verkeerslicht wachtende auto's door het rode licht waarbij hij linksaf sloeg. Hij kon een hem tegemoetkomende auto nog net ontwijken, maar schepte daarna een fietser, die over de auto heen door de lucht vloog, op het wegdek terechtkwam en daar zwaargewond bleef liggen. De dader reed met onverminderde snelheid door. Hij werd vervolgd en veroordeeld voor poging tot doodslag op de fietser. ${ }^{5}$

Buiten het verkeer treffen we vergelijkbare gevallen in de rechtspraak aan. In het wilde weg om zich heen schieten en daarbij iemand dodelijk treffen leidde tot veroordeling voor doodslag. Door in een café met een barkruk te zwaaien aanvaardde de dader volgens de rechter willens en wetens de kans een bijstander te raken en te verwonden; hij werd veroordeeld voor de door het Openbaar Ministerie tenlastegelegde mishandeling.

Er is ook enige jurisprudentie (doch slechts weinig) waaruit blijkt dat hier grenzen zijn. Dat er zo weinig rechtspraak is waarin wordt gezegd: dit geval levert géén (voorwaardelijk) opzet op, komt vanzelfsprekend mede omdat eerst de (individuele) vervolgingsbeslissing wordt genomen. Denk aan het bekend ge-worden Vlissingse drama: een jeugdige motorrijder raast voor de zoveelste maal over de weg, binnen de bebouwde kom van Vlissingen, met $150 \mathrm{~km} / \mathrm{u}$. Hij verliest de macht over het stuur en schept een zevenjarig meisje, dat op slag gedood wordt. Hij wordt voor dood door schuld (art. 6 WVW) vervolgd. Als het Openbaar Ministerie wel gekozen zou hebben voor vervolging terzake van doodslag, zou dat, gezien de ernst van deze vorm van wegpiraterij, naar mijn in-schatting zeker kans van slagen hebben gehad.

5 Een ander voorbeeld (laveloos rijden) biedt Rb Utrecht, VR 1993, no. 6. 
Terug naar de weinige gevallen waarin wel voor een opzetmisdrijf werd vervolgd, maar niet met succes. Het bekendste voorbeeld is het Porsche-arrest van de Hoge Raad. ${ }^{6}$ Hier maakte de hoogste nationale rechter duidelijk dat er ook grenzen zijn. Als een onder invloed van alcohol verkerende wegpiraat die na een reeks van levensgevaarlijke handelingen een dodelijk ongeval heeft veroorzaakt, niet alleen het leven van anderen, maar ook dat van zichzelf in gevaar heeft gebracht, moet de rechter in zijn oordeel betrekken, aldus de Hoge Raad, dat behoudens aanwijzingen voor het tegendeel - niet waarschijnlijk is dat de ver-dachte ook zijn eigen dood op de koop heeft toegenomen. In een dergelijk geval zou dus niet zo gemakkelijk voorwaardelijk opzet op de ingetreden dood van anderen (en daarmee doodslag op die anderen) kunnen worden aangenomen. De onderhavige strafzaak werd door de Hoge Raad verwezen naar een andere rechter, die de veroordeling beperkte tot het subsidiair ten laste gelegde culpose misdrijf van art. 6 WVW. Hier komt de wil als psychische component van het opzet toch weer naar voren. Enerzijds valt positief te waarderen dat grenzen worden gesteld aan het voorwaardelijk opzet, wat eigenlijk alleen goed kan met behulp van de wilsfactor. Anderzijds moet erkend worden dat het niet erg overtuigend is om juist bij de hier vertoonde zeer ernstige vorm van wegpiraterij geen voorwaardelijk opzet aan te nemen.

\section{De wettelijke strafbedreigingen}

Op dit grensvlak tussen voorwaardelijk opzet als onderkant van opzet en grove roekeloosheid als bovenkant van culpa wordt het enorme verschil in strafbe-dreiging tussen opzetvarianten en culpose varianten door velen als zeer onbevredigend gevoeld. Vandaar ook de roep om meer vervolgingen terzake van doodslag, respectievelijk zware mishandeling. Een andere mogelijkheid om tegemoet te komen aan de wens om gevallen van grove roekeloosheid strenger strafrechtelijk te kunnen aanpakken is verhoging van de aan culpose misdrijven verbonden strafbedreigingen. Hierboven wees ik er al op dat bijvoorbeeld het Duitse strafrecht hier een vloeiender overgang in wettelijke strafpositie kent. In Nederland is naar anleiding van enkele geruchtmakende gevallen van wegpiraterij (onder andere het bovengenoemde Vlissingse drama) zeer recent een wet in werking getreden die de aan de misdrijven van art. 6 WVW verbonden strafmaxima aanzienlijk verhoogt. Onder de nieuwe wet staat op dood door schuld bij gelegenheid van een verkeersongeval maximaal 3 jaar gevangenisstraf. Is tevens sprake van drankmisbruik of forse snelheidsoverschrijding, dan bedraagt het strafmaximum het drievoudige en gaat dus naar 9 jaar. Aldus kan de maximum straf oplopen tot 12 jaar in het geval dat er meer slachtoffers zijn gevallen.

6 HR 15 oktober 1996, NJ 1997, 199 m.nt. 'tH; AA 1997, p. 438 m.nt. J. de Hullu. 
Naar mijn smaak is deze nieuwe regeling te weinig genuanceerd. De keuze van de twee situaties die tot aanzienlijke verhoging van de strafbedreiging leiden (alcoholmisbruik en veel te hard rijden) komt over als willekeurig en opportu-nistisch ontleend aan enkele actuele gevallen. Een algehele heroverweging door de wetgever van de aan culpose misdrijven verbonden strafbedreigingen zou hier op haar plaats zijn; die zou tot een genuanceerdere en evenwichtiger uitkomst kunnen leiden. Dit schijnt overigens thans op het departement van justitie in studie te zijn.

\section{Slot}

Op dit punt ben ik van opvatting dat de aan culpose misdrijven verbonden straf-bedreigingen inderdaad aan de lage kant zijn en dat verhoging zeker te verde-digen en zelfs wenselijk is. Naar mijn oordeel is dan een integrale herziening van de strafmaxima voor culpose delicten wenselijk. Er zijn zorgplichten die vergelijkbaar zijn met die in het verkeer, zoals in het spoorweg- en luchtver-keer, in de bouw; denk verder aan andere reeds door mij genoemde sectoren: bedrijven, ziekenhuizen e.d., het milieu. Door de voortschrijdende techniek neemt de kans op ernstige fouten en ongelukken toe. Het gevolg daarvan is dat er een steeds grotere verantwoordelijkheid ontstaat voor 'functionarissen'. En dat mag zich ingeval van ernstige fouten van 'functionarissen' met fatale gevol-gen, dus ingeval van door dergelijke functionarissen gepleegde culpose delicten, ook vertalen in wat hogere strafmaxima dan thans het geval is. Ik verwijs nog-maals naar het Duitse strafrecht. Maar dan hoort men mij spreken over ernstige fouten, en daarmee wil ik zeggen dat verhoging van de strafbedreiging voor culpose delicten, als men daarvoor kiest, gepaard zou moeten gaan met het weer gaan stellen van serieuze, zelfstandige eisen aan de aanmerkelijke schuld. En dan zitten we weer aan de andere kant van het spectrum, aan de onderkant van de culpa. Dus enerzijds verhoging van de strafbedreigingen voor een aantal culpose delicten, niet alleen voor art. 6 WVW); anderzijds verhoging van de ondergrens voor het aannemen van aanmerkelijke schuld. Wat dit laatste betreft, hoop ik dus dat veel feitenrechters de culpa als zelfstandig misdrijfbestanddeel wél een substantiële inhoud geven en het culpose misdrijf niet gelijk willen stellen aan een door het fatale gevolg tot misdrijf gekwalificeerde overtreding van een gedragsregel. 